NASA Technical Memorandum 102002

AIAA-89-1144

\title{
Unsteady Blade Pressure Measurements on a Model Counterrotation Propeller
}

\author{
(SASA-IU-102002) CASTEADI EIALE EBESSUEE \\ N89-2C779 \\ LEASUEEAEATS CN ACLEL CCOBIELCTATION \\ EFCEELLEE (NAS1) $22 \mathrm{~F}$ CSCL $20 A$ \\ Uaclas
$63 / 71 \quad C 19 \& 952$
}

Laurence J. Heidelberg and Richard P. Woodward

Lewis Research Center

Cleveland, Ohio

Prepared for the

12th Aeroacoustics Conference

sponsored by the American Institute of Aeronautics and Astronautics

San Antonio, Texas, April 10-12, 1989 
UNSTEADY BLADE PRESSURE MEASUREMENTS ON A MODEL COUNTERROTATION PROPELLER

\author{
Laurence J. Heidelberg and Richard P. Woodward \\ National Aeronautics and Space Administration \\ Lewis Research Center \\ Cleveland, Ohio 44135
}

\begin{abstract}
SUMMARY
In an exploratory effort an advanced counterrotation propeller instrumented with blade-mounted pressure transducers was tested in the NASA Lewis 9- by 15-Foot Anechoic Wind Tunnel at a simulated takeoff and landing speed of Mach 0.20. The propeller's aft diameter was reduced to investigate possible noise reductions resulting from reduced blade row interaction with the tip vortex. The propeller was tested at three blade row spacings at fixed blade setting angles, at the maximum blade row spacing at higher blade setting angles, and at propeller axis angles of attack up to $\pm 16^{\circ}$ to the flow. A limited number of unsteady blade surface pressure measurements were made on both rotors of the model counterrotation propeller. Emphasis was placed on determining the effects of rotor-rotor interactions on the blade surface pressures. A unique method of processing the pressure signals was developed that enables even weak interaction waveforms and spectra to be separated from the total signal. The interaction on the aft rotor was many times stronger than that on the forward rotor. The fundamental rotor interaction tone exhibited complicated behavior but generally increased with rotational speed and blade setting angle and decreased with rotor spacing. With the propeller axis at an angle to the flow, the phase response of the aft rotor appeared to be significantly affected by the presence of the forward rotor.
\end{abstract}

\title{
INTRODUCTION
}

The next generation of commercial airliners is likely to be powered by an advanced turboprop that offers the promise of considerable fuel savings while still allowing for a cruise speed similar to that of current turbofan aircraft. Advanced counterrotation propellers may offer from 8 to 10 percent additional fuel savings over similar single-rotation propellers at cruise conditions (ref. 1). However, there is considerable concern about the potential noise generated by such aircraft, which includes both in-flight cabin noise and community noise during takeoff and landing. More noise sources are present in counterrotation propellers than in single-rotation propellers. The aerodynamic interaction of the two rotors results in unsteady blade loading, which in turn radiates to the far field as interaction tones. These interaction tones are a major contributor to the noise of counterrotation propellers. Blade surface pressure measurements could provide a better understanding of rotor interactions. Little or no measurements of unsteady blade pressures are available for counterrotation propellers.

In this exploratory investigation a limited number of unsteady blade surface pressure measurements were made on both rotors of a model counterrotation propeller. Emphasis was placed on determining the effects of rotor-rotor interactions on the blade surface pressures. In order to accomplish this, a unique method of processing the pressure signals was developed that enabled the

Copyright (C) 1989 by the American Institute of Aeronautics and Astronautics, Inc. No copyright is asserted in the United States under Title 17, U.S. Code. The U.S. Government has a royalty-free license to exercise all rights under the copyright claimed herein for Governmental purposes.

All other rights are reserved by the copyright owner. 
waveforms to be separated from the total signal. This paper presents data for a model counterrotation propeller that was tested in the NASA Lewis 9- by 15-Foot Anechoic Wind Tunnel. The test results are for Mach 0.20, which is representative of takeoff and landing operation. The test propeller (designated F7/A3) had 11 forward and 9 aft blades. The aft propeller had a smaller diameter than the forward propeller to reduce its interaction with the forward propeller tip vortices. This interaction is thought to be a major contributor to the noise of counterrotation propellers (refs. 2 and 3 ).

The propeller was tested at three rotor spacings at fixed blade setting angles to investigate spacing effects and at the maximum blade row spacing at higher blade setting angles to investigate loading effects. It was operated over a range of rotational speeds corresponding to forward rotor tip speeds from 191 to $259 \mathrm{~m} / \mathrm{sec}$ ( 626 to $850 \mathrm{ft} / \mathrm{sec}$ ) and at propeller axis angles of attack (inflow angles) up to $\pm 16^{\circ}$. Much of the acoustic data obtained for these configurations is presented in reference 4 .

\section{APPARATUS AND PROCEDURE}

\section{Wind Tunnel and Model}

The NASA Lewis 9- by 15-Foot Anechoic Wind Tunnel is located in the lowspeed return loop of the 8- by 6-Foot Supersonic Wind Tunnel. The maximum airflow velocity is slightly over Mach 0.20, which provides a takeoff and landing test environment. The tunnel acoustic treatment provides anechoic conditions down to a frequency of $250 \mathrm{~Hz}$, which is lower than the range of the fundamental tones produced by the F7/A3 propeller. Figure 1 shows a model counterrotation propeller installed in the tunnel. The acoustic instrumentation is clearly evident. A complete description of this instrumentation can be found in reference 4. The installed propeller was powered by two independent air turbine drives, allowing the option of different rotational speeds. The two rotors were designed to run at the same speed, but they were operated at about 100-rpm difference to relieve the higher test rig stress experienced with nearly equal rotational speeds.

The front propeller (F7) is $62.2 \mathrm{~cm}(24.5 \mathrm{in.})$ in diameter, but the aft propeller's diameter was reduced to investigate expected acoustic benefits associated with avoiding the impingement of the upstream propeller's tip vortex wake on the downstream propeller. The model propeller was run in the $11 \times 9$ blade configuration, with blade setting angles for essentially equal torque between the two blade rows. This also resulted in a nearly equal thrust split for the test conditions. Table I also presents propeller design characteristics at a cruise condition of Mach 0.72 .

Table II shows the propeller test conditions for which data are reported herein. The model was operated at inflow angles up to $\pm 16^{\circ}$. The propeller was tested at a forward blade setting angle of $36.4^{\circ}$ (measured at 0.75 radius) and an aft blade setting angle of $43.5^{\circ}$ at three blade row spacings. The propeller was also tested at higher blade setting angles of $41.1^{\circ}$ and $46.4^{\circ}$ at the maximum blade row spacing. There is some question as to which blade setting angles and tip speeds should be chosen to minimize noise while providing the necessary takeoff thrust. Higher blade setting angles with a corresponding 
reduction in rotational speed (to maintain the same thrust) may lower the propeller noise. This would suggest that the more highly loaded blade angle may be more typical of desired full-scale operation. The blade row spacing is presented in terms of the physical axial spacing between the upstream and downstream blade pitch change axes.

Figure 2 shows plan views of the F7/A3 and F7/A7 blading. The A7 blades were the original full-diameter blades designed to go with the F7 blades. Note that the smaller-diameter $A 3$ blade has a corresponding chord increase so that it can maintain the same thrust as the $A 7$ blade (at the same rotational speed but with a higher $A 3$ blade setting angle).

\section{Blade-Mounted Pressure Transducers}

Four Kulite miniature pressure transducers were mounted on four different blades in the positions shown in figure 3(a). Two transducers were installed on the front rotor ( $F 7$ blades) and two on the aft rotor (A3 blades). All transducers were located at the 0.75 radius and 0.15 chord station, where the reference radius used for the $A 3$ blade was the radius of the original $A 7$ blade. For each rotor one blade-mounted pressure transducer (BMT) measured the pressure surface of the blade and the other the suction surface. The transducers were mounted to measure the pressure through a 1.55-mm-diameter hole drilled through the blade, as shown in figure $3(b)$. A room-temperature vulcanizing (RTV) silicone adhesive was used for bonding in order to ensure that the transducers were strain isolated from the blade. The RTV adhesive was also used to fair the BMT's into the blade surface.

The BMT's were calibrated by applying a fluctuating pressure of known level and frequency directly to the installed BMT's. The gain of the amplified output signal was adjusted to get the correct voltage. Reference 5 describes the calibration technique in detail. Signals from the BMT's were taken off the rotors by using frequency-modulated (FM) telemetry. The telemetry system was not designed for four-arm bridge transducers. Wiring and components external to the telemetry module were used to correct this deficiency but only permitted installation of four transducers. Wiring problems were encountered during testing. These problems caused broken, or complete loss of, signal at times. Thus, a complete set of data for all four BMT's and all operating conditions was not available. One BMT located at the pressure-surface station on the forward rotor experienced signal loss at all operating speeds above 20 percent of design.

The telemetry system's frequency response was $20 \mathrm{kHz}$. These signals along with both rotor once-per-revolution signals were recorded on FM tape. The recorded signals were then digitized at a rate of approximately 256 samples per interaction period. An interaction period is defined here as the time it takes for blade 1 on the forward rotor to pass by all the blades on the aft rotor. For counterrotating blade rows operating at the same speeds, this period would be one-half of the period of a rotor revolution. In addition, for some of the data run with the propeller axis at an angle to the flow, the signals were also digitized at a rate of 128 samples per revolution so that they could be averaged synchronous to the once-per-revolution pulse. 
Since the primary concern in this investigation was the interaction of the rotors, a method was developed to average the pressure signals in the time domain synchronous to the interaction frequency. This was done to greatly reduce all signals that were not coherent to the interaction frequency. Without this processing it would not have been possible to accurately view the waveforms nor in many cases the spectra produced by the rotor interactions. The processing used for counterrotation was similar to the time-domain averaging commonly used for single-rotation machinery. The difference was that instead of averaging synchronous to the once-per-revolution signals (pulses), synchronization to the once-per-relative-revolution signals (interactions) was used. Since there was no pulse to signal the start of each interaction period, one was calculated during post-test processing.

The following is a brief description of the signal processing used: The digital information was processed on a mainframe computer to produce 100 time ensembles of 10 interaction periods each. By using the once-per-revolution signals (pulses), the time ensembles were formed synchronous to the rotor interaction. This was done by calculating the azimuthal angle of blade 1 on both rotors. For every data sample the azimuthal angle was known when a data sample contained the once-per-revolution pulse. The angle for subsequent samples was determined by a known rotational speed and sample rate and the number of samples since the pulse was last detected. When the azimuthal angles of both blades were equal, the interaction period was started. This point in time was used to synchronize the time ensembles and the interactions within the ensembles. Synchronization was maintained by adding or subtracting one sample so as to hold an exact 256-samples-per-interaction period. If errors of more than one sample were found, the period and the entire ensemble it was part of were rejected. The number of samples per revolution was also monitored, and data were rejected when the deviation was more than one sample from the average (approx. 512 samples/rev). The ensembles were averaged (time-domain averaging) to produce waveforms. The fast Fourier transform (FFT) was used to produce enhanced spectra and phase (azimuthal) angles. In addition, FFT's were taken of the individual time ensembles of data and then averaged in the frequency domain. These spectra were used to monitor data quality and to obtain an overview of all parts of the pressure signal. All spectra produced were in terms of interaction orders (I) or shaft orders (P).

For some of the inflow angle conditions additional processing of the 128-samples-per-revolution data was done. This processing simply involved synchronizing each revolution of data to the once-per-revolution pulse. A more completed description of this process is contained in reference 5 .

\section{RESULTS AND DISCUSSION}

\section{Rotor Interaction Tone}

The effects of rotor spacing, rotational speed, and blade setting angle on the blade surface pressure of the F7/A3 counterrotation propeller were investigated. Emphasis was placed on the interaction tones and their harmonics, since they are the source of much noise for counterrotation propellers.

The aft rotor blades cutting through the flow leaving the forward rotor blades was expected to have the largest interaction. Figure $4(a)$ shows a fairly typical waveform of the suction surface of an aft rotor blade. The 
rotors were at 90 percent of design speed and the rotor spacing was nominal. The BMT was located at 0.75 radius and 0.15 chord as were all the BMT's. This waveform was produced by synchronously averaging 100 interaction periods. Each period represented $360^{\circ}$ of rotation of the forward rotor relative to the aft. The plot shows 11 cycles contained within the $360^{\circ}$; each cycle was caused by the flow from an individual forward rotor blade. The blade-to-blade variation in setting angle and shape was probably the cause of the variations between the 11 waveforms. The sawtooth waveform resulted from variations in both the angle and magnitude of the velocity in the forward rotor exit flow. The FFT of this waveform is shown in figure $4(b)$. Included in this figure is the frequencydomain-averaged spectrum shown by the dotted line. The spectrum shows the fundamental tone or blade passing order (BPO) at the 11 th interaction (order 11 I). Nine harmonics of this tone are present, indicating a highly nonsinusoidal waveform. The separation between the time- and frequency-domainaveraged spectra is almost an order of magnitude where no coherence to the interaction frequency exists.

The waveform and spectrum for the suction surface of the forward rotor blade at the same operating point are shown in figure 5 . Here the waveform indicates nine cycles per interaction corresponding to the nine blades of the aft rotor. Since the aft rotor is downstream, the mechanism of the interaction must be one that can propagate upstream, such as a potential flow field or acoustic waves. The magnitude of this interaction was more than an order of magnitude $(20 \mathrm{~dB})$ below that of the flow interactions on the aft rotor. The spectrum of the forward rotor shows much lower harmonic content than that of the aft rotor, indicating a more sinusoidal waveform. Only the fundamental BPO significantly penetrated the broadband of the frequency-domain-averaged spectrum. This is a good example of the need to synchronously average in the time domain, since much of the interaction signal was below the broadband and the shaft order tones.

Effect of rotational speed. - The effect of rotational speed on the amplitude of the BPO tone and its harmonics in terms of the unsteady pressure coefficient $C_{p}$ is shown in figures 6 to 8 for all three rotor spacings.

The unsteady pressure data were normalized by dividing by the dynamic pressure $q$ at the radial location of the measuring station to produce a pressure coefficient. The $q$ was calculated from the tunnel static pressure and the estimated blade relative Mach number. Helical Mach number (vector sum of tangential velocity and forward velocity) was not used, since it does not account for the swirl and increase in axial velocity on the aft rotor caused by the forward rotor. In an attempt to improve upon the estimated $q$ the axial Mach number both entering and exiting the forward rotor was estimated from momentum theory and measured thrust. Swirl velocity leaving the forward rotor was estimated from the measured torque. The values of dynamic pressure used to obtain the pressure coefficients are listed in table III.

The BMT on the forward rotor blade at the suction-surface station is shown in figure 6 . The fundamental BPO generally showed an increase with speed for all rotor spacings. There was a progressive decrease in level with harmonic number. The higher harmonics were generally insensitive to speed, with the exception of the second harmonic at maximum spacing. 
The BMT suction-surface data for the aft rotor are shown in figure 7 . The behavior of the BPO tone for the aft rotor was much more complicated. At the maximum rotor spacing it increased with speed until 90 percent, where there was a reversal of slope. At the nominal rotor spacing it increased very rapidly with speed at all speeds. The minimum rotor spacing produced an unusual minimum in the BPO at 90-percent speed. For the minimum spacing at 90-percent speed all higher harmonics shown had higher levels than the fundamental. The levels of the higher harmonics generally decreased with harmonic number and were insensitive to speed.

The response of the pressure-surface BMT for the aft rotor is shown in figure 8. The BPO tone showed no large trends as a function of speed, with the exception of the jump in the nominal spacing data at 90-percent speed. The response of this pressure-surface BMT was lower than that of the suction surface. Previous investigations (refs. 5 and 6 ) have shown that the suctionsurface BMT's near the leading edge are very sensitive to inflow angle changes. In addition to sensitivity, this location has shown a large nonlinear response to inflow angle changes. For this reason we believe that the pressure-surface BMT's may provide a better indication of rotor inflow conditions.

Effect of rotor spacing. - The effect of rotor spacing on the amplitude of the BPO tone is shown in figure 9 for the forward rotor BMT on the suction surface. The level of the BPO increased as the spacing was decreased, with the exception of 95-percent speed, where the maximum and nominal spacing reversed the trend. It was generally expected that the interaction effects would increase with decreasing spacing as was the general case for the forward rotor. The BPO level on the aft rotor had a more complex response to the spacing, as shown in figure 10. The maximum and nominal spacing showed the expected trend. The minimum spacing data also showed the expected trend at 70- and 75-percent speed but a reversal at higher speeds with a much lower level than the nominal, and in many cases, the maximum-spacing data. A look at the higher harmonics in figure 7 shows no large trends with spacing. This indicates that the fine structure of the blade wake profile was much the same and that only the level of the fundamental changed. Lower levels of the BPO tone imply a more uniform velocity profile (in terms of the fundamental). The reason for a more uniform velocity profile at minimum spacing was not immediately clear.

Effect of blade setting angle. - All of the previous data presented were for $b$ lade setting angles of $36.4^{\circ}$ and $43.5^{\circ}$ for the forward and aft blades, respectively. For the maximum rotor spacing only, the blade setting angles were increased to $41.1^{\circ}$ and $46.4^{\circ}$, respectively. The blade loading at these higher setting angles is thought to be more representative of full-scale operation. The BPO pressure levels for these two sets of blade angles for the forward rotor are compared in figures 11 and 12 . The suction-surface BMT (fig. 11) shows a very large increase in BPO level for the higher blade setting angles. About the only unusual feature at this location is a decrease in level at 90-percent speed for the high blade setting angles. The suction-surface BMT for the aft rotor had a more complicated behavior, as shown in figure 12(a). For most of the speed range the higher blade setting angle configuration had higher BPO pressure levels, but slightly above 85-percent speed this trend reversed. The pressure-surface BMT for the aft rotor had higher BPO levels at the higher blade setting angles for all speeds, as shown in figure $12(b)$. Between 85- and 90-percent speed a very large increase for the higher blade setting angles was observed. 
Note that changes in BPO levels can result from changes in the unsteady pressure response of the blades as a function of reduced frequency or local flow phenomena such as a leading-edge vortex. Since there is no guarantee of linear pressure response to inflow conditions or constant response with frequency, these data provide only a qualitative guide to the inflow conditions of each rotor.

\section{Angular Inflow}

The F7/A3 was run at inflow angles up to $\pm 16^{\circ}$. These data were digitized and processed twice: first synchronous to the interaction frequency, and then synchronous to the rotational speed. Most of the response to angular inflow can be seen in the rotational speed synchronous processing.

An interesting feature of the BMT signals for angular inflow can be seen in figure 13, where the frequency-domain-averaged (nonsynchronous) spectrum for $16^{\circ}$ inflow is compared with the zero inflow angle spectrum. These spectra are for the suction-surface BMT of the aft (A3) rotor at 90-percent speed. With no angular inflow the spectrum is dominated by the BPO and its harmonics (fig. 13(a)). The BPO occurred at the 11 th interaction order, corresponding to the 11 blades of the forward rotor. For $16^{\circ}$ inflow (fig. 13(b)) there were several tones on either side (sidebands) of the BPO and its harmonics. Each of these tones was spaced one shaft order $P$ (approx. one-half an interaction order I) apart. We think that this was for the most part a result of the modulation of the spacing of the 11 blade wakes in response to the once-perrevolution loading change (frequency modulation). Modulation of the exit vector diagram of the forward rotor blades in response to the 1-P loading may also have contributed to some amplitude modulation of the blade pressure. The peak tone tended to be lower in frequency than the BPO tone, perhaps because blade wakes that are further apart are also stronger. The fact that there were several sidebands and the BPO (carrier frequency) was smaller than some of the sidebands is strong evidence of frequency modulation. The strong tone in figure 13(b) at $1 \mathrm{P}$ (approx. 1/2 I) is a result of the once-per-revolution loading change imposed by the angular inflow. The angular inflow on the forward rotor caused an azimuthal variation of the velocity vector entering the aft rotor. The swirl component of the velocity probably had the greatest effect on the aft rotor $1-P$ loading.

The once-per-revolution, synchronous, time-averaged pressure waveform for the suction-surface BMT on both rotors is shown in figure 14 for 90-percent speed and an inflow angle of $16^{\circ}$. The azimuthal angle used in this figure was that of the forward rotor, with zero at the top of the tunnel and the positive angle in the direction of rotation. Since the aft rotor rotated in the opposite direction, it was plotted from right to left $\left(360^{\circ}\right.$ to $\left.0^{\circ}\right)$ so as to be consistent with the forward rotor's azimuthal angle scale. When the propeller was at positive yaw angles to the flow (to the left in fig. 1), a nearly sinusoidal variation of the instantaneous blade angle of attack occurred with a maximum at zero degrees for the forward rotor. Maximum loading on the suction surface is indicated by a minimum pressure. The waveform for the forward rotor blade shows a minimum pressure just past the zero angle, indicating a phase lag between the blade angle of attack and the pressure. The FFT analysis of this waveform showed a phase lag of $25^{\circ}$. This is similar to results obtained for a single-rotation propeller (ref. 6). The aft rotor had a minimum pressure near 
$270^{\circ}$. This was somewhat surprising, since a simple model, where the forward rotor is not present, suggested that the minimum would occur near an azimuthal angle of $180^{\circ}$. Thus, it would appear that the pressure was leading the blade angle of attack by a substantial amount $\left(87^{\circ}\right)$. Since this is not likely, the forward rotor must be responsible for a significant change in the location (azimuthal angle) of maximum loading on the aft rotor. One effect that would change the location of maximum loading is swirl leaving the forward rotor. An estimate of the average swirl yielded a displacement of $12^{\circ}$ in the direction of forward rotor rotation for the data shown. This would result in an apparent lead of $12^{\circ}$ on the aft rotor. A larger effect could be the lag in the blade forces relative to angle. The swirl velocity in the forward rotor exit flow would be expected to lag the angle of attack by the same amount as the blade forces lagged. Although this might be considerably larger than the effect of swirl displacement, it is still not enough to explain the large difference $\left(87^{\circ}\right.$ in measured lead plus the $15^{\circ}$ to $20^{\circ}$ expected lag in pressure response). If the aft rotor had been run without the forward rotor and the BMT response (lag angle) to inflow angle measured, the actual location of maximum angle of attack for the counterrotation case could be determined. The whole subject of the propagation of inflow distortion through a counterrotation propeller needs further investigation.

The magnitude and phase angle of the 1-P pressure response to a $16^{\circ}$ inflow angle are shown in figure 15 as a function of percent of design speed. The suction-surface BMT for the forward rotor had a magnitude that increased with speed, as shown by the magnitude of the unsteady pressure coefficient $C_{p}$. The phase angle shown in this figure is in terms of lead and lag from the forcing function (i.e., blade angle-of-attack change). For a zero phase angle a pressure-surface BMT would peak at maximum blade angle of attack, but a suctionsurface BMT would be at a minimum. The angles shown represent a lead or lag from this condition. The suction-surface BMT for the forward rotor showed a small increase in phase lag, from $-17^{\circ}$ to $-25^{\circ}$, as the rotational speed increased. The aft rotor suction surface had a similar $C_{p}$ level but a more complicated response to speed, with a minimum at 80-percent speed. The phase angle showed a lead of $101^{\circ}$ at 70 -percent speed that decreased to $87^{\circ}$ at 90-percent speed. The pressure-surface BMT for the aft rotor had a $C_{p}$ magnitude that was less than half that of the suction surface and decreased with speed. The phase angle for the pressure surface had a lead of $53.5^{\circ}$ at 70-percent speed that decreased to $50.6^{\circ}$ at higher speed. This was considerably less lead than the suction surface had. Although it is unusual for the pressure and suction surfaces not to have similar phase lags or leads, in this case the smaller phase lead of the pressure surface is easier to explain in terms of the swirl exit velocity lag of the forward rotor and may be more indicative of overall trends.

The pressure coefficient for the first shaft order is shown as a function of inflow angle for 90-percent speed in figure 16. Both suction-surface BMT's have steeper slopes than the pressure-surface BMT, as might be expected. The slope of the aft rotor decreased with increasing angle; the forward rotor had the opposite characteristic. The pressure-surface BMT had a very linear response to inflow angle as has been seen in previous single-rotation investigations. 


\section{SUMMARY OF RESULTS}

In an exploratory effort, an advanced counterrotation propeller instrumented with a very limited number of blade-mounted pressure transducers was tested in the NASA Lewis 9- by 15-Foot Anechoic Wind Tunnel at a simulated takeoff and landing speed of Mach 0.20. The propeller's aft diameter was reduced to investigate possible noise reductions resulting from reduced blade row interaction with the tip vortex. The propeller was tested at three blade row spacings at fixed blade setting angles, at the maximum blade row spacing at higher blade setting angles, and at propeller axis angles of attack (inflow angles) up to $\pm 16^{\circ}$. The unsteady blade surface pressures were measured on both rotors of the model counterrotation propeller. Emphasis was placed on determining the effects of rotor-rotor interactions on the blade surface pressures. These unsteady pressures result in the interaction tones that are of much concern in the noise signature. The following results were obtained:

1. A unique method of processing the pressure signals was developed that enabled even weak interaction waveforms and spectra to be separated from the total signal. This processing method is based on time-domain averaging synchronous to the interaction frequency.

2. The fundamental rotor-rotor blade pressure interaction tone was generally 5 to 20 times stronger on the aft rotor than on the forward rotor. The waveform of the forward rotor interaction was fairly sinusoidal, but the aft rotor had high levels at higher harmonics.

3. The fundamental interaction that occurred at the blade passing order (BPO) generally increased with speed, with some notable exceptions. The higher harmonics had no overall trends with speed.

4. For the most part the fundamental rotor-rotor blade pressure interaction tone increased with decreasing rotor spacing.

5. The interaction strengths generally increased at the higher blade setting angles.

6. For the angular inflow condition the rotor interaction occurred at several tones spaced one shaft order apart on either side of the BPO tone and its harmonics.

7. The forward rotor's response to angular inflow in terms of phase response (azimuthal location of maximum loading) was similar to that of a single-rotation propeller. The phasing of the aft rotor response was greatly affected by the presence of the forward rotor.

\section{REFERENCES}

1. Mikkelson, D.C., Mitchel1, G.A., and Bober, L.J., "Summary of Recent NASA Propeller Research," Aerodynamics and Acoustics of Propellers, AGARD CP-366, AGARD, Neuilly-Sur-Seine, France, 1985, pp.12-1 to 12-24 (NASA TM-83733).

2. Dittmar, J.H., "Some Design Philosophy for Reducing the Community Noise of Advanced Counter-Rotation Propellers," NASA TM-87099, 1985. 
3. Dittmar, J.H. and Stang, D.B., "Noise Reduction for Model Counterrotation Propeller at Cruise by Reducing Aft-Propeller Diameter," NASA TM-88936, 1987.

4. Woodward, R.P. and Gordon, E.B., "Noise of a Model Counterrotation Propeller With Reduced Aft Rotor Diameter at Simulated Takeoff/Approach Conditions (F7/A3)," AIAA Paper 88-0263, Jan. 1988 (NASA TM-100254).

5. Heidelberg, L.J. and Woodward, R.P., "Advanced Turboprop Wing Installation Effects Measured by Unsteady Blade Pressure and Noise," AIAA Paper 87-2719, Oct. 1987 (NASA TM-100200).

6. Heidelberg, L.J. and Clark, B.J., "Preliminary Results of Unsteady Blade Surface Measurements for the SR-3 Propeller, "AIAA Paper 86-1893, July 1986 (NASA TM-87352).

TABLE I. - DESIGN CHARACTERISTICS OF F7/A3 COUNTERROTATION PROPELLER

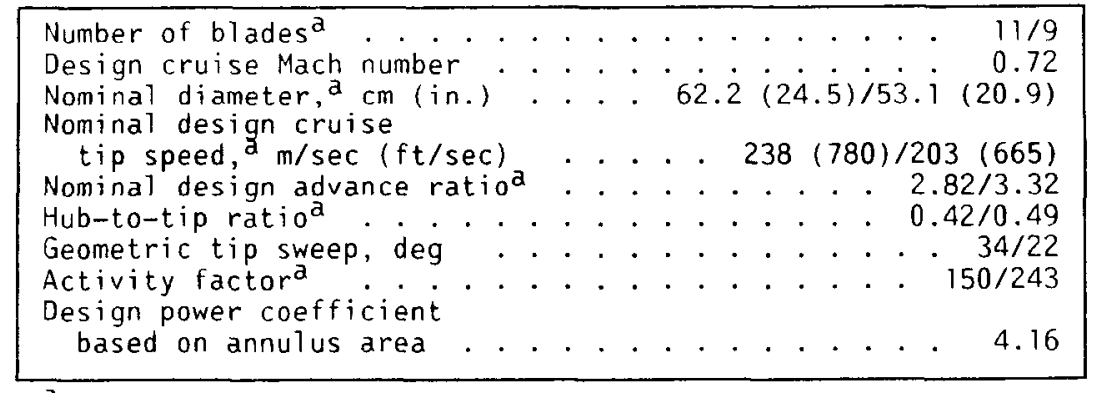

afront rotor/rear rotor.

TABLE II. - TEST CONDITIONS

\begin{tabular}{|c|c|c|c|c|}
\hline \multirow[t]{2}{*}{$\begin{array}{c}\text { Blade setting } \\
\text { angles, } \\
\text { deg }\end{array}$} & \multicolumn{2}{|c|}{$\begin{array}{l}\text { Blade row spacing } \\
\text { between pitch } \\
\text { change axes }\end{array}$} & \multirow[t]{2}{*}{$\begin{array}{l}\text { Inflow } \\
\text { angle, } \\
\text { deg }\end{array}$} & \multirow{2}{*}{$\begin{array}{l}\text { Rotational } \\
\text { speed, a } \\
\text { percent of } \\
\text { design }\end{array}$} \\
\hline & $\mathrm{cm}$ & in. & & \\
\hline $36.4 / 43.5$ & $b_{8.48}$ & 3.34 & $\begin{array}{c}0 \\
\pm 8, \pm 16\end{array}$ & $\begin{array}{l}70-95 \\
70-90\end{array}$ \\
\hline $36.4 / 43.5$ & $c_{10.57}$ & 4.16 & $\begin{array}{c}0 \\
\pm 8, \pm 16\end{array}$ & $\begin{array}{l}70-95 \\
70-90\end{array}$ \\
\hline $36.4 / 43.5$ & $\mathrm{~d}_{14.99}$ & 5.90 & $\begin{array}{c}0 \\
\pm 8, \pm 16\end{array}$ & $\begin{array}{l}70-95 \\
70-90\end{array}$ \\
\hline $41.1 / 46.4$ & $d_{14.99}$ & 5.90 & $\begin{array}{c}0 \\
\pm 8, \pm 16\end{array}$ & $\begin{array}{l}70-90 \\
70-90\end{array}$ \\
\hline
\end{tabular}

${ }^{2} 100$-percent speed $=8371 \mathrm{rpm}$ for both rotors.

binimum.

CNominal.

dMaximum. 
TABLE III. - DYNAMIC PRESSURES USED TO OBTAIN PRESSURE COEFFICIENTS

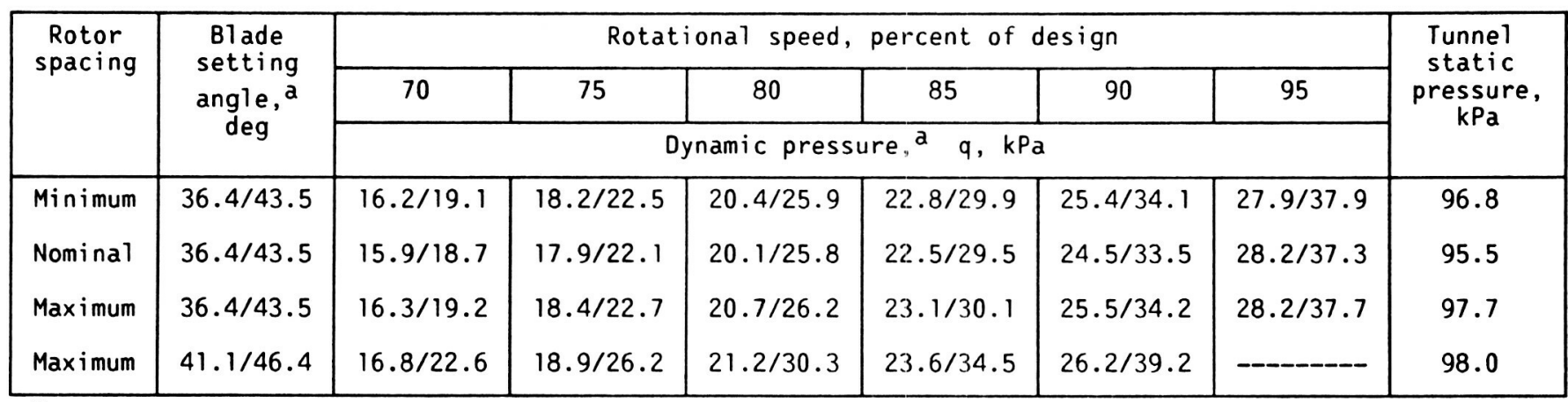

aforward rotor/aft rotor.

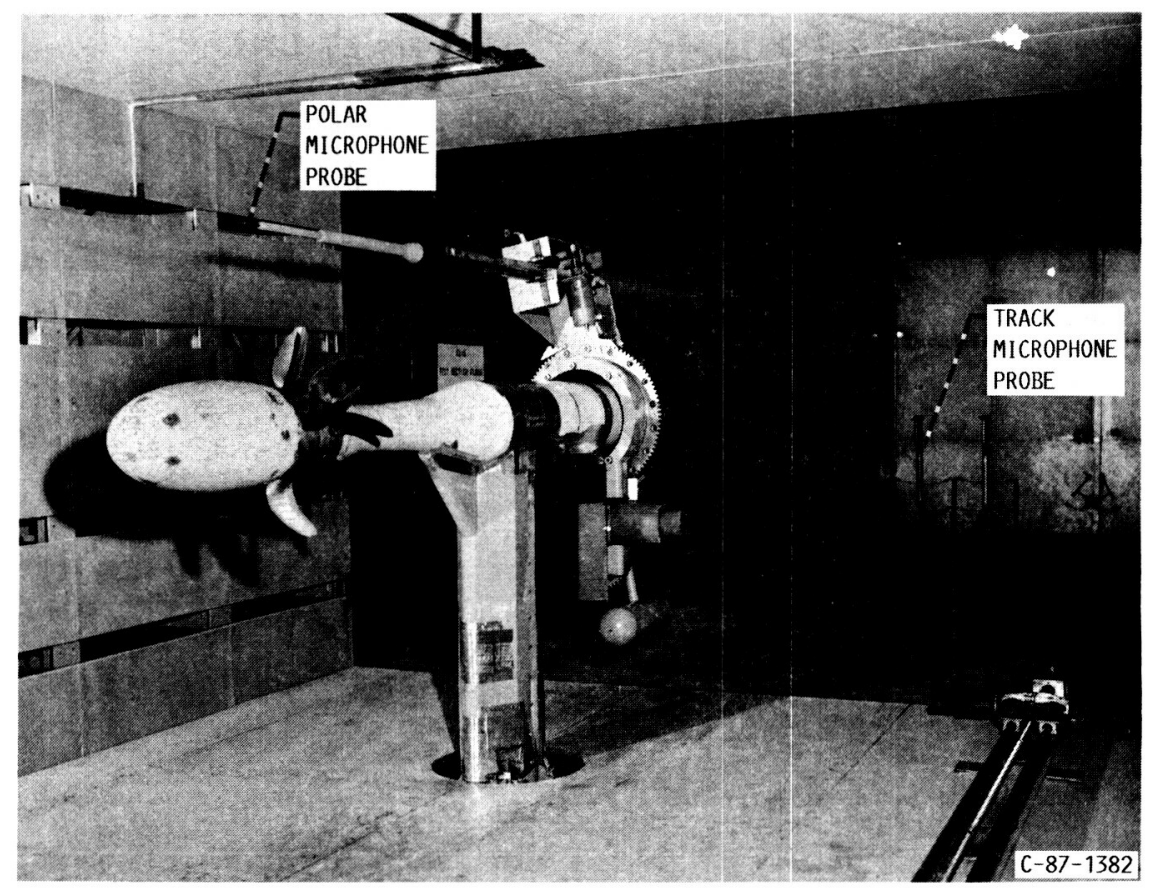

FigURE 1. - COUNTERROTATION TURBOPROP MODEL IN 9- BY 15-FO0T ANECHOIC WIND TUNNEL. 

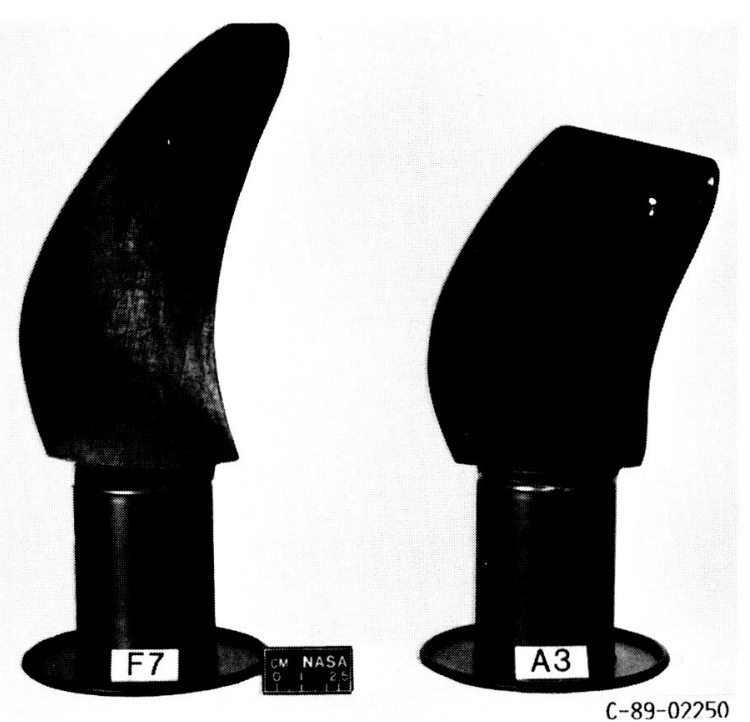

(A) F7/A3, REDUCED-DIAMETER AFT PROPELLER

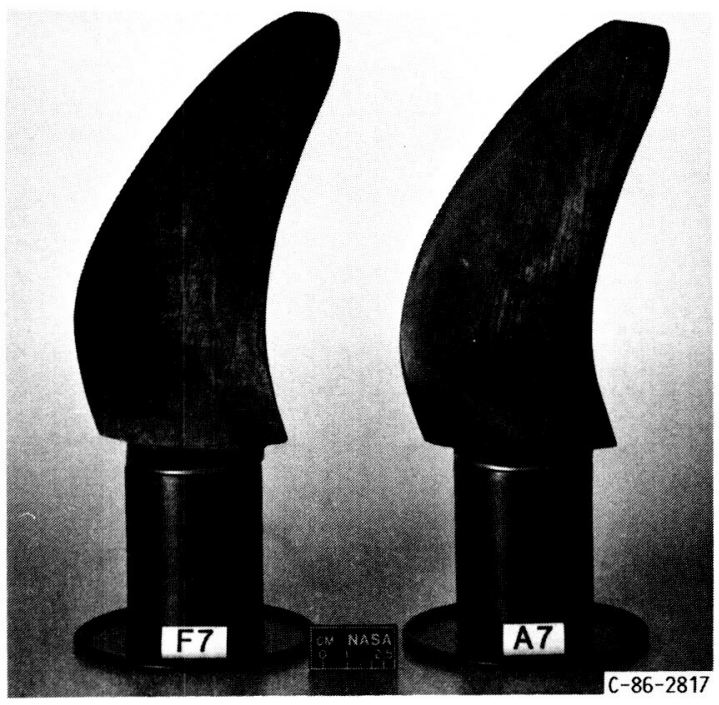

(B) F7/A7.

FIGURE 2. - PROPELLER CONFIGURATIONS.
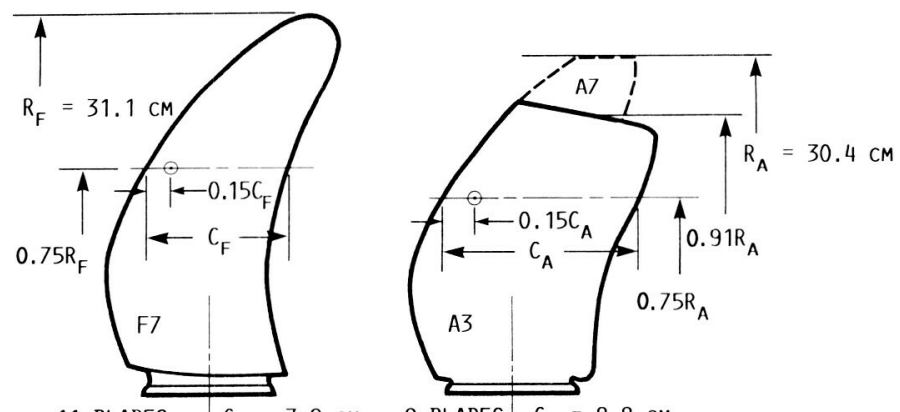

11 BLADES $\quad C_{F}=7.2 \mathrm{~cm}$

9 BLADES $^{-C_{A}}=8.8 \mathrm{~cm}$

(A) PRESSURE TRANSDUCER LOCATIONS: TWO BLADES INSTRUMENTED ON EACH ROTOR, ONE ON PRESSURE SURFACE, THE OTHER ON SUCTION SURFACE.

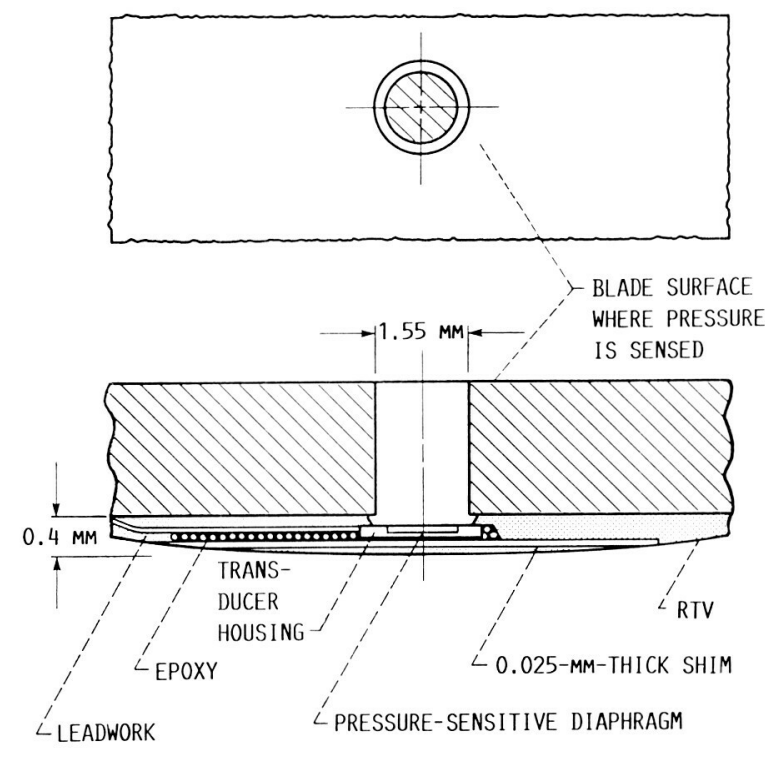

(B) TYPICAL INSTALLATION OF BLADE-MOUNTED PRESSURE TRANSDUCER SENSING THROUGH BLADE.

FIGURE 3. - BLADE-MOUNTED PRESSURE INSTRUMENTATION. 


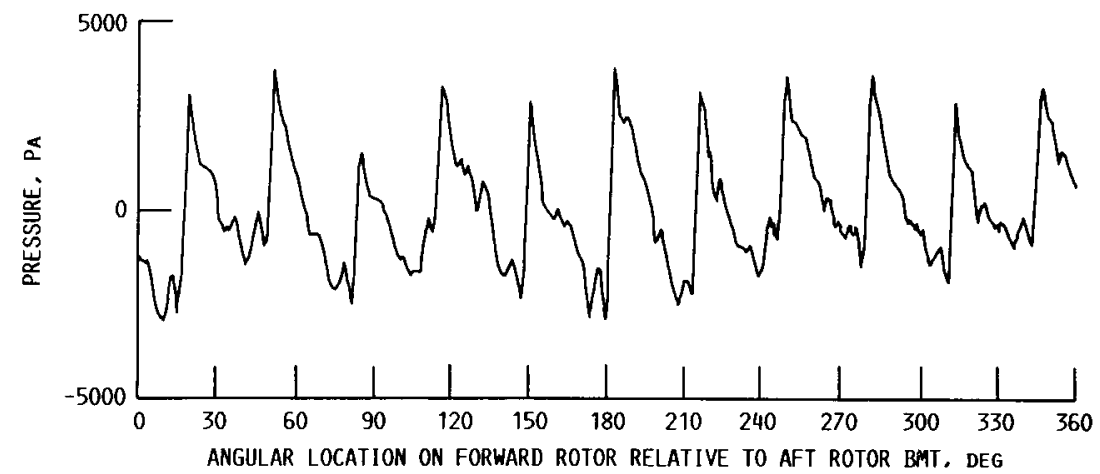

(A) WAVEFORM.

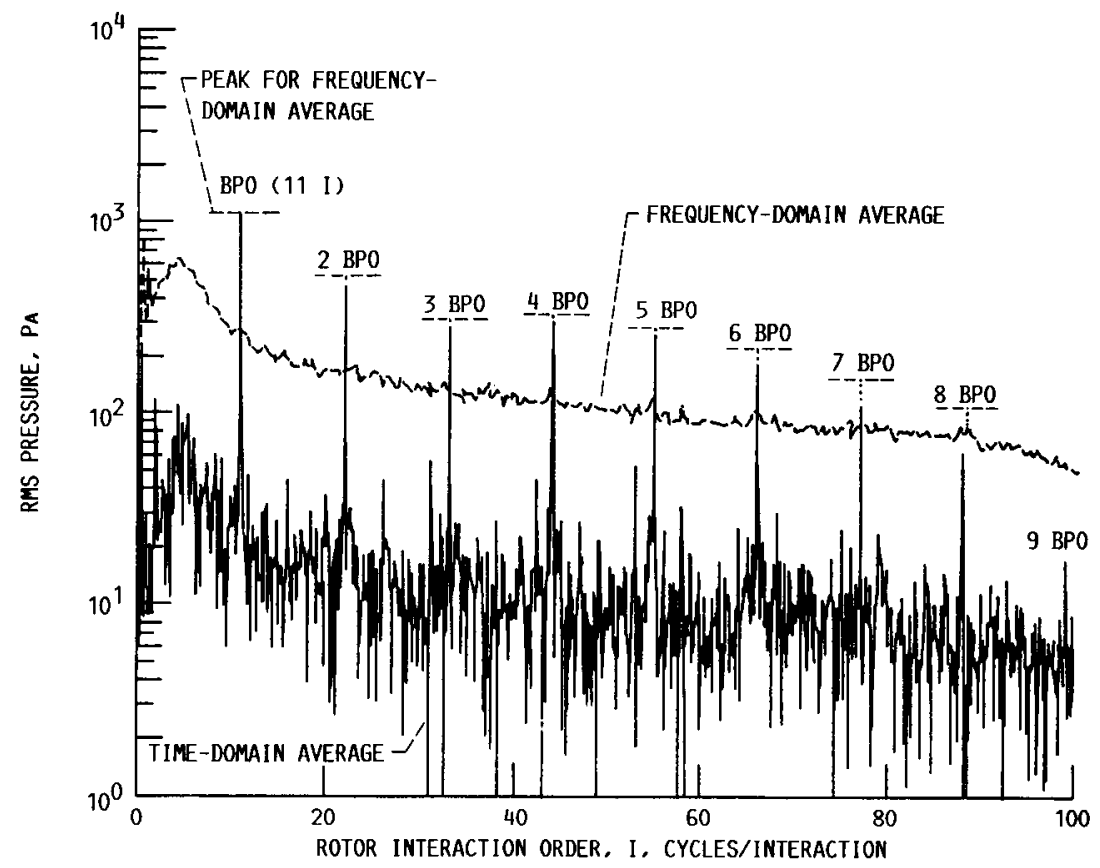

(B) SPECTRUM.

FIGURE 4. - TYPICAL BLADE PRESSURE INTERACTION OF FORWARD ROTOR ON AFT ROTOR. BMT LOCATION: 0.15 CHORD, 0.75 RADIUS ON A3 SUCTION SURFACE, 100 AVERAGES: ROTATIONAL SPEED, 90 PERCENT OF DESIGN: BLADE SETTING ANGLES, $36.4^{\circ}$ AND 43. $5^{\circ}$; NOMINAL SPACING. 


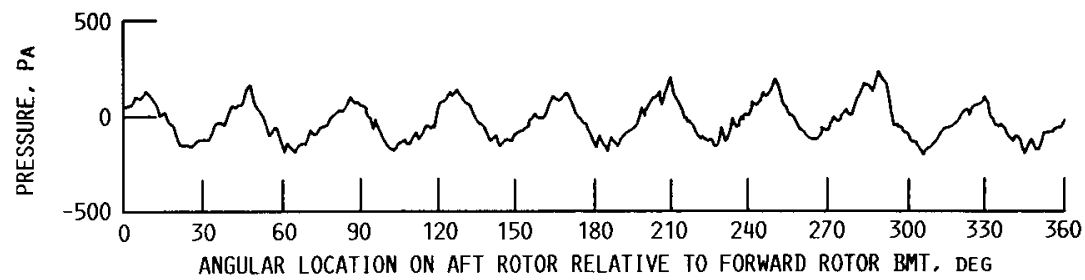

(A) WAVEFORM.

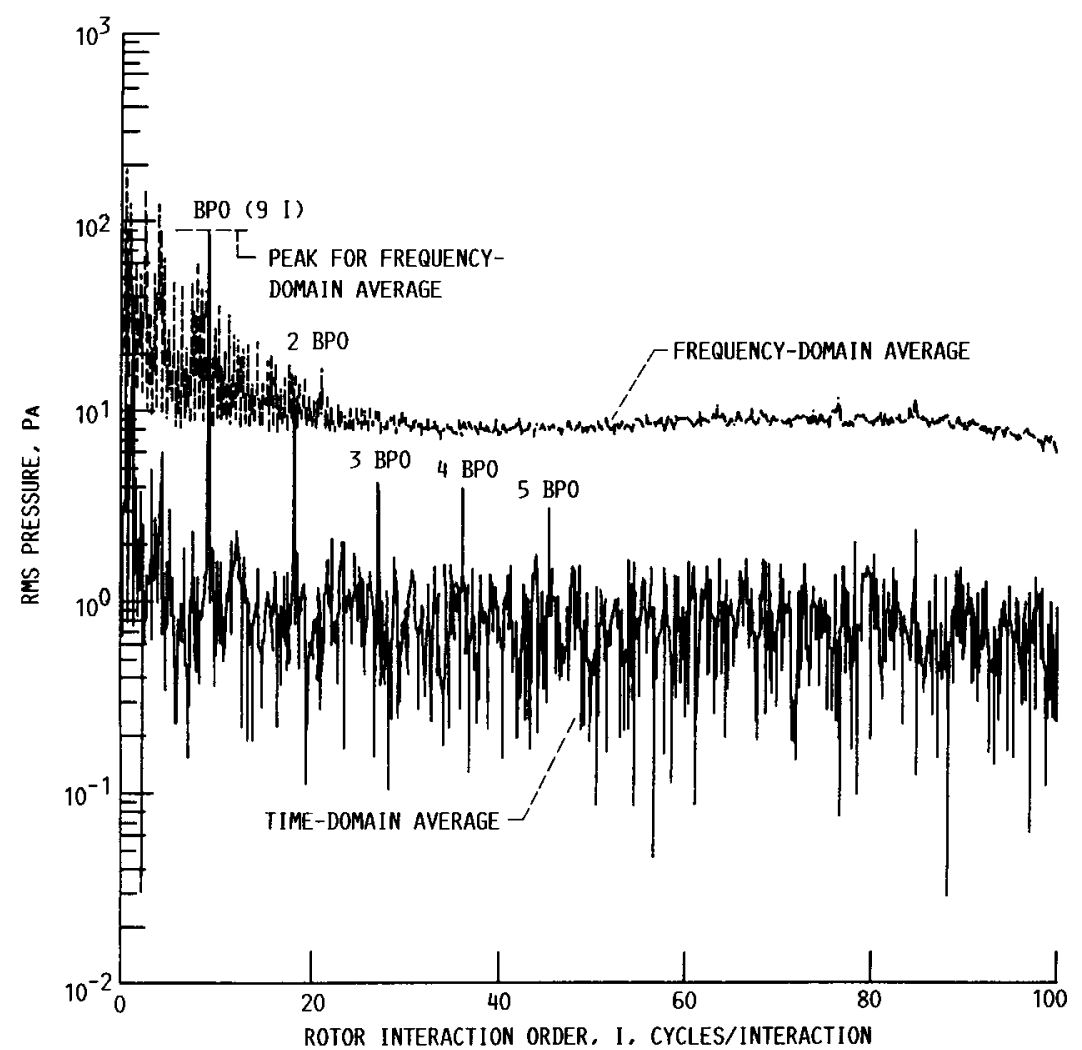

(B) SPECTRUM.

FIGURE 5. - TYPICAL BLADE PRESSURE INTERACTION OF AFT ROTOR ON FORWARD ROTOR. BMT LOCATION: 0.15 CHORD, 0.75 RADIUS ON F7 SUCTION SURFACE. 100 AVERAGES; ROTATIONAL SPEED, 90 PERCENT OF DESIGN: BLADE SETTING ANGLES, $36.4^{\circ}$ AND 43.5 $5^{\circ}$; NOMINAL SPACING. 

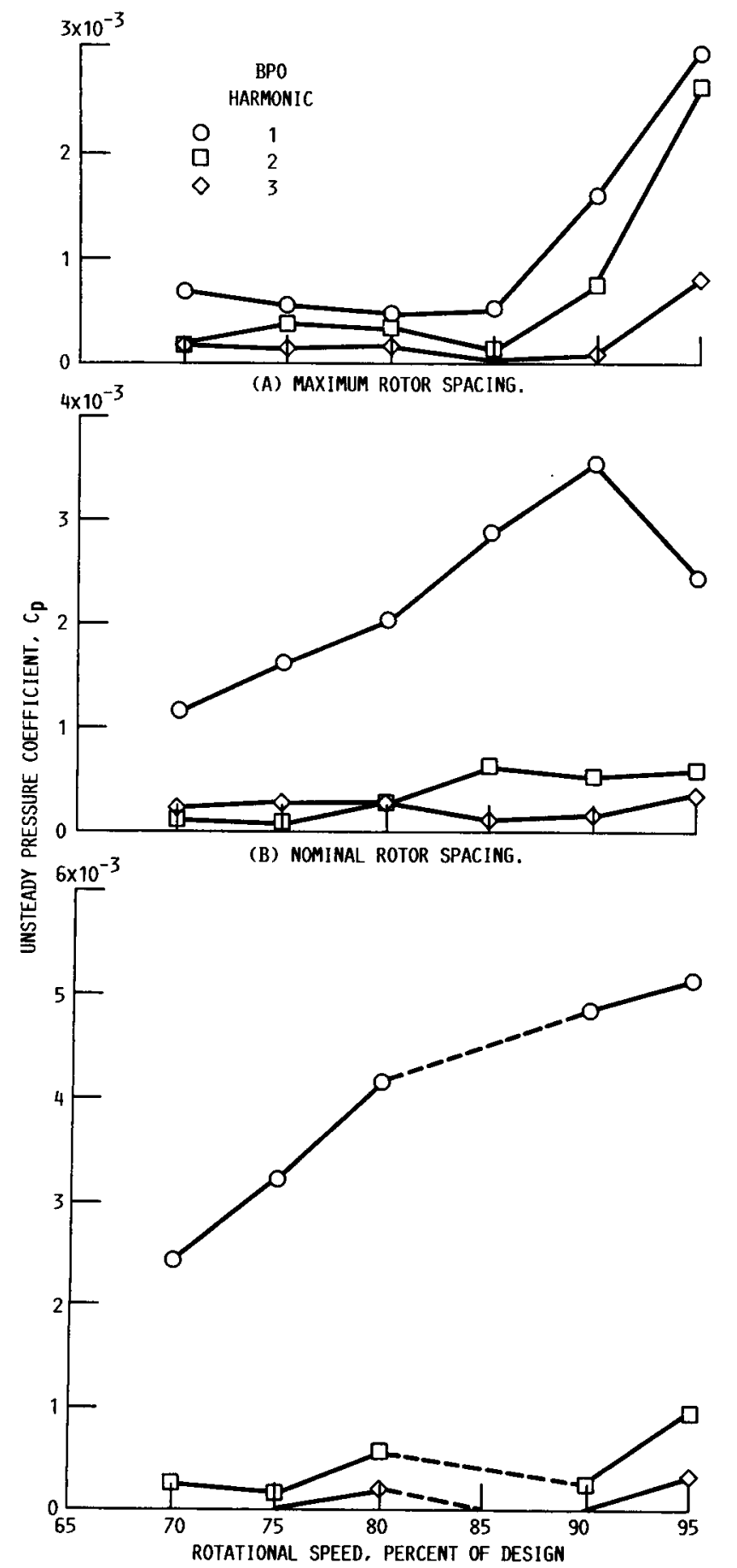

(C) MINIMUM ROTOR SPACING.

FIGURE 6. - EFFECT OF ROTATIONAL SPEED ON BLADE PASSING ORDER AND ITS HARMONICS FOR FORWARD ROTOR BLADE (F7), SUCTION SURFACE.
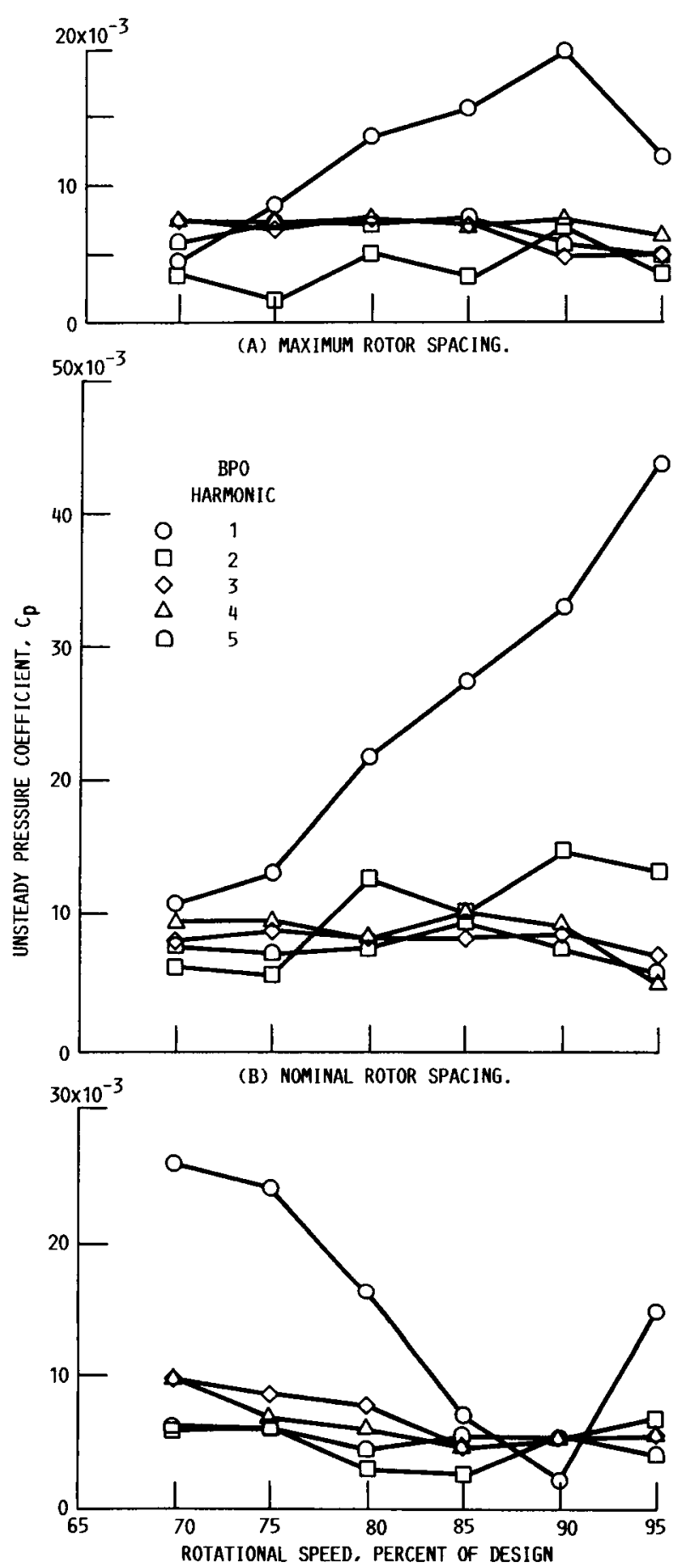

(C) MINIMUN ROTOR SPACING.

FIGURE 7. - EFFECT OF ROTATIONAL SPEED ON BLADE PASSING ORDER AND ITS HARMONICS FOR AFT ROTOR BLADE (A3). SUCTION SURFACE. 


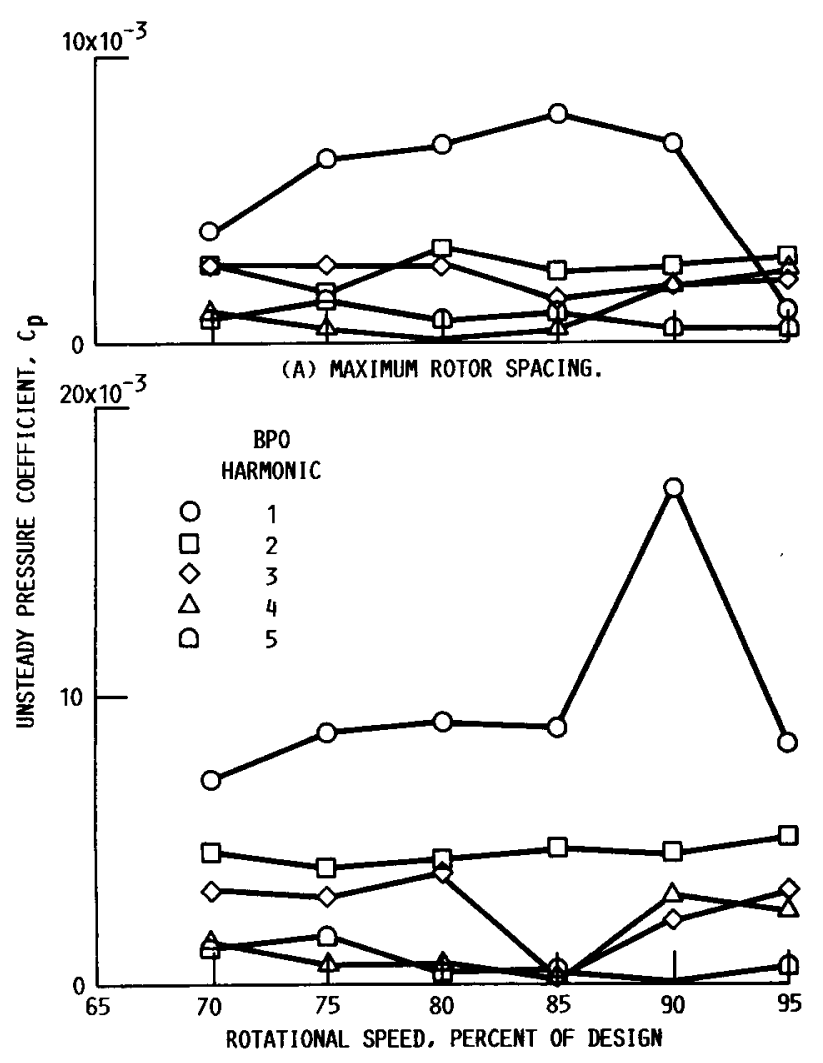

(B) NOMINAL ROTOR SPACING.

FIGURE 8. - EFFECT OF ROTOR SPEED ON BLADE PASSING ORDER AND ITS HARMONICS FOR AFT ROTOR BLADE (A3), PRESSURE SURFACE.

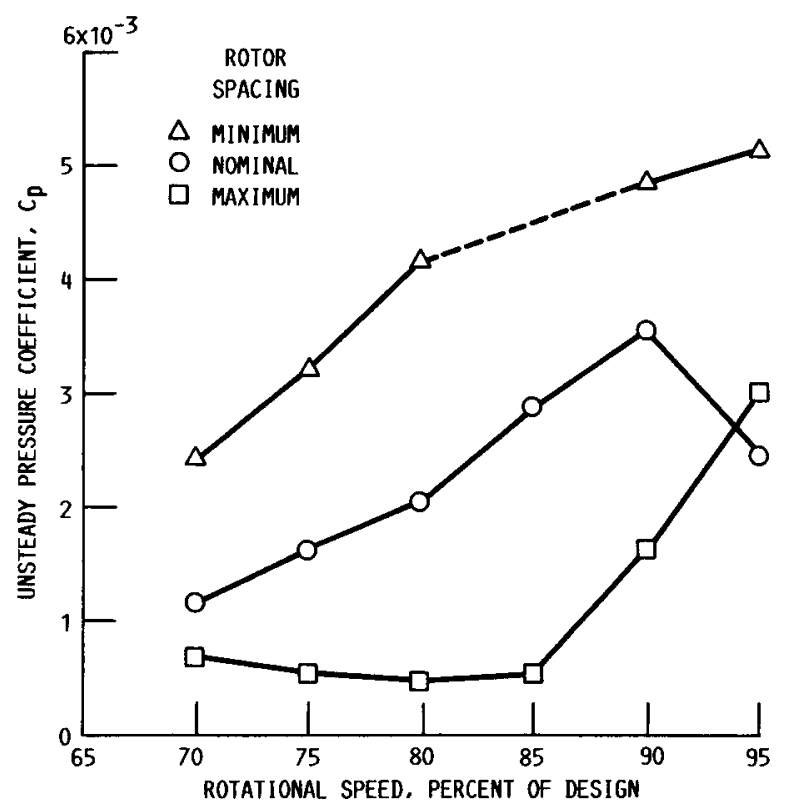

FIGURE 9. - EFFECT OF ROTOR SPACING ON BLADE PASSING ORDER TONE FOR FORWARD ROTOR BLADE (F7). SUCTION SURFACE. 


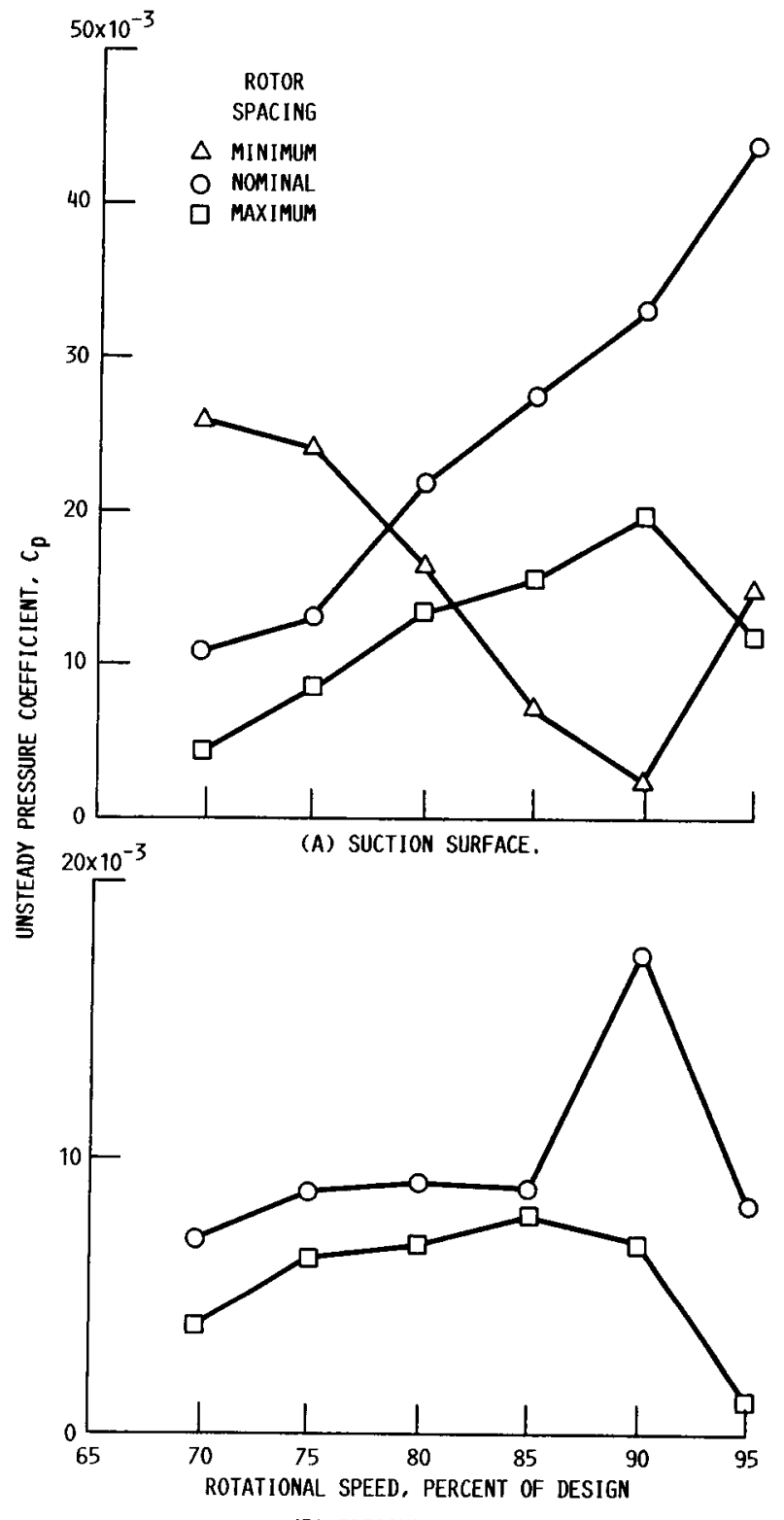

(B) PRESSURE SURFACE.

FIGURE 10. - EFFECT OF ROTOR SPACING ON BLADE PASSING ORDER TONE FOR AFT ROTOR BLADE (A3).

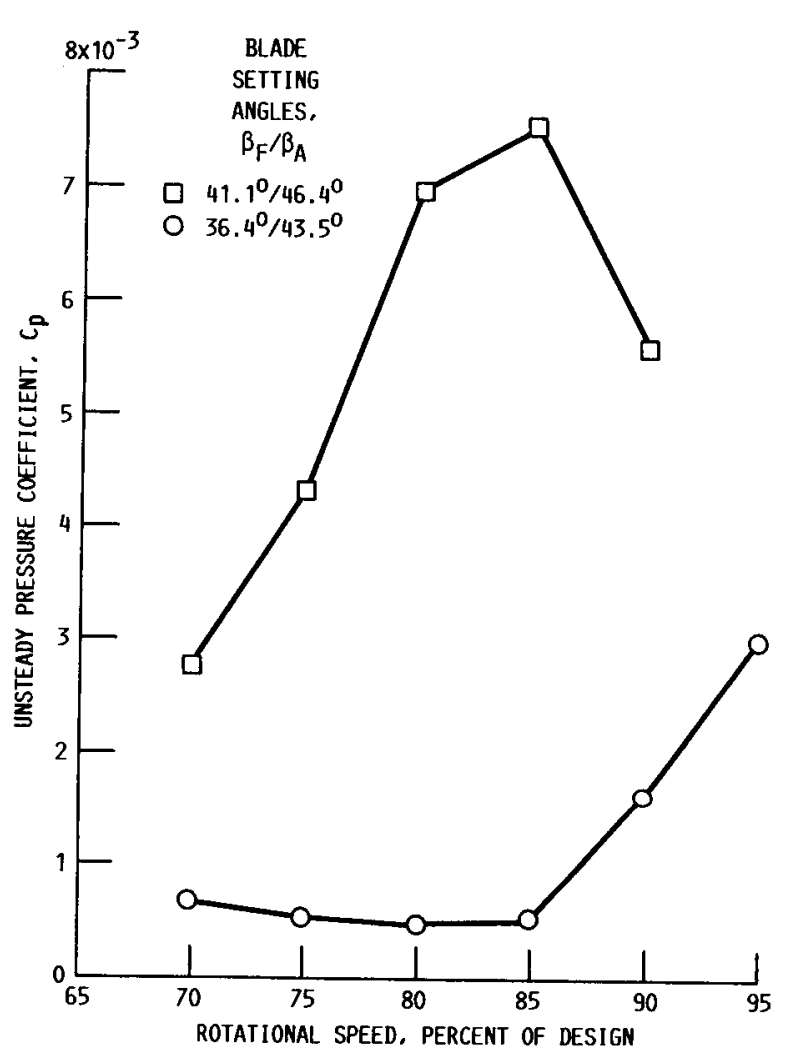

FIGURE 11. - EFFECT OF BLADE SETTING ANGLES ON BLADE PASSING ORDER TONE FOR FORWARD ROTOR BLADE (F7), SUCTION SURFACE. 


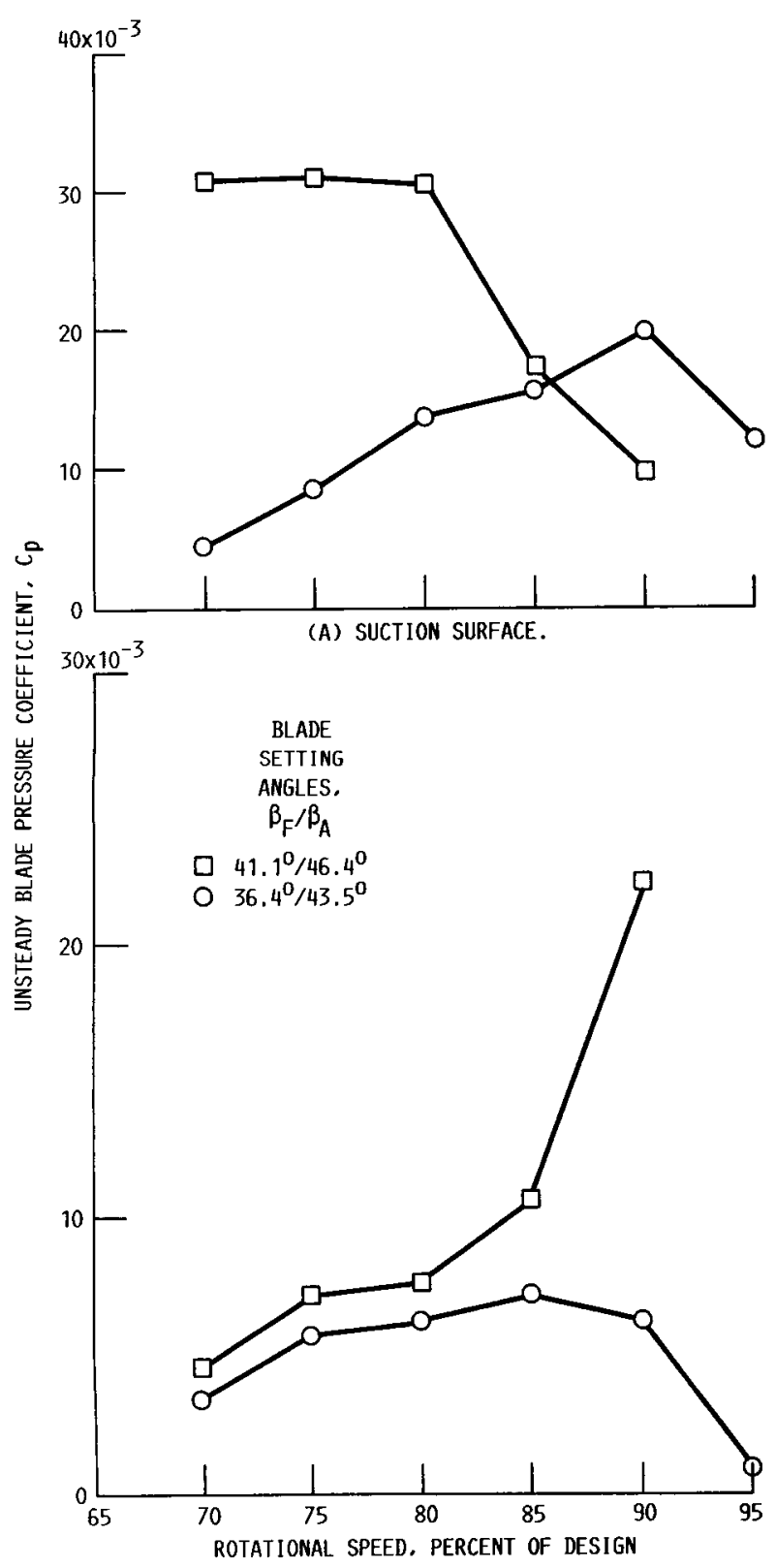

(B) PRESSURE SURFACE.

FIGURE 12. - EFFECT OF BLADE SETTING ANGLES ON BLADE PASSING ORDER TONE FOR AFT ROTOR BLADE (A3).

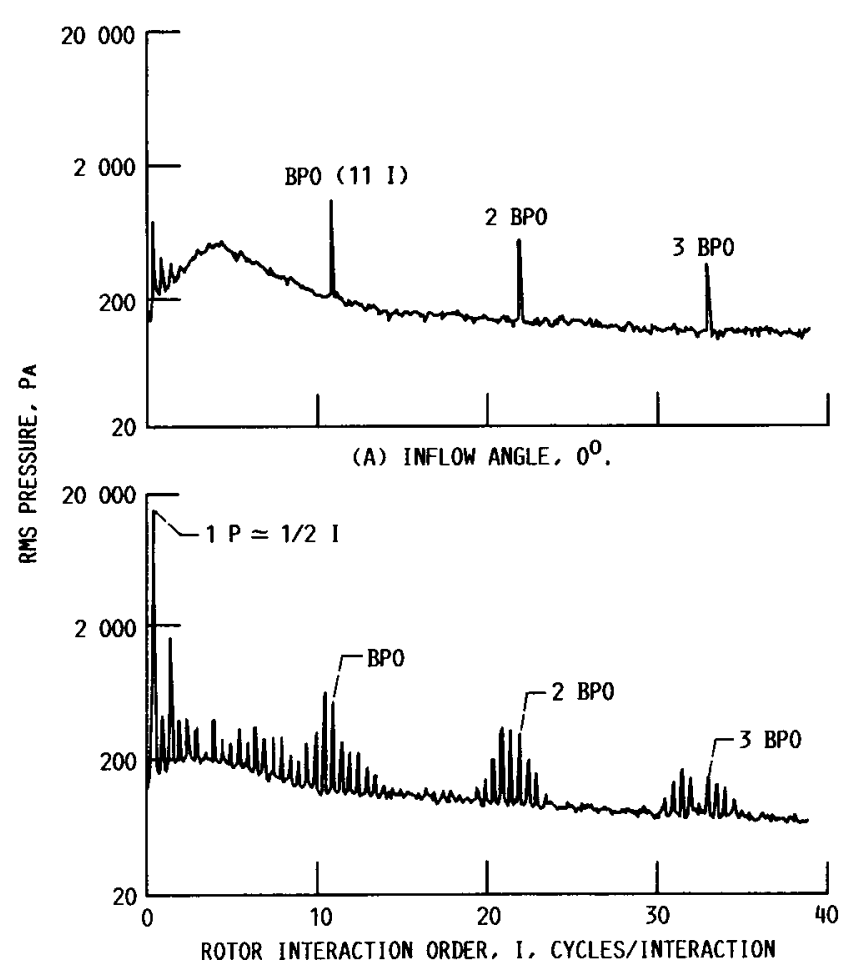

(B) INFLOW ANGLE, $16^{\circ}$.

FIGURE 13.- EFFECT OF INFLOW ANGLE ON FREQUENCY-DOMAINAVERAGED SPECTRUM OF AFT (A3) ROTOR BLADE PRESSURE. SUCTION SURFACE; ROTATIONAL SPEED. 90 PERCENT OF DESIGN. 


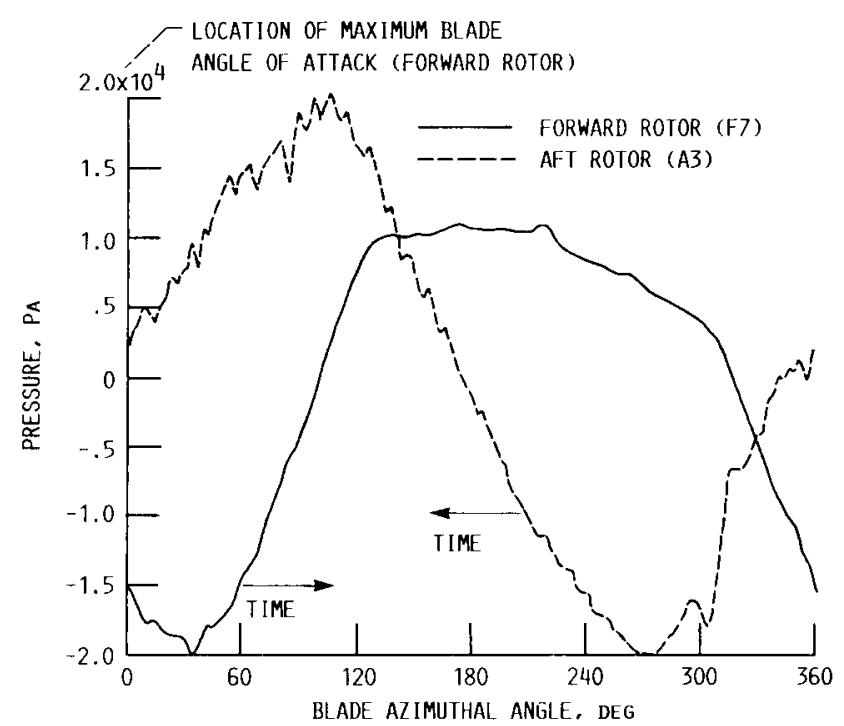

FIGURE 14. - AVERAGED WAVEFORM FOR SUCTION-SURFACE PRESSURE OF BOTH FORWARD AND AFT ROTOR BLADES AT INFLOW ANGIE OF $16^{\circ}$. ROTATIONAL SPEED, 90 PERCENT OF DESIGN.
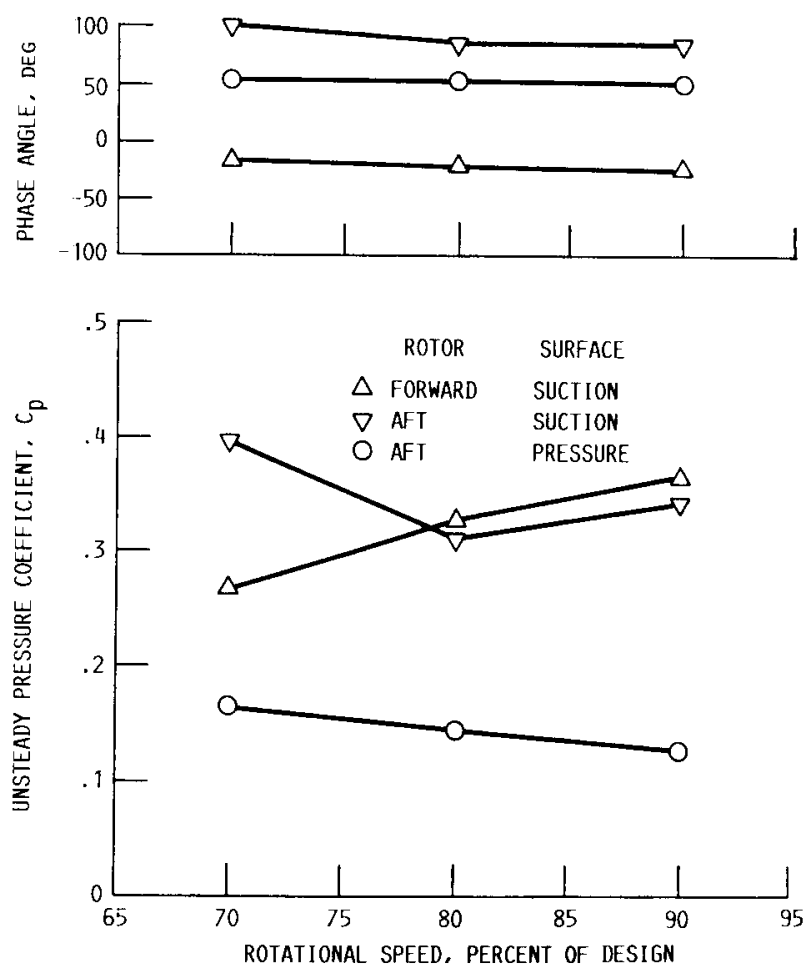

FIGURE 15. - UNSTEADY PRESSURE RESPONSE TO $16^{\circ}$ INFLOW ANGLE. NOMINAL SPACING: FIRST SHAFT ORDER.

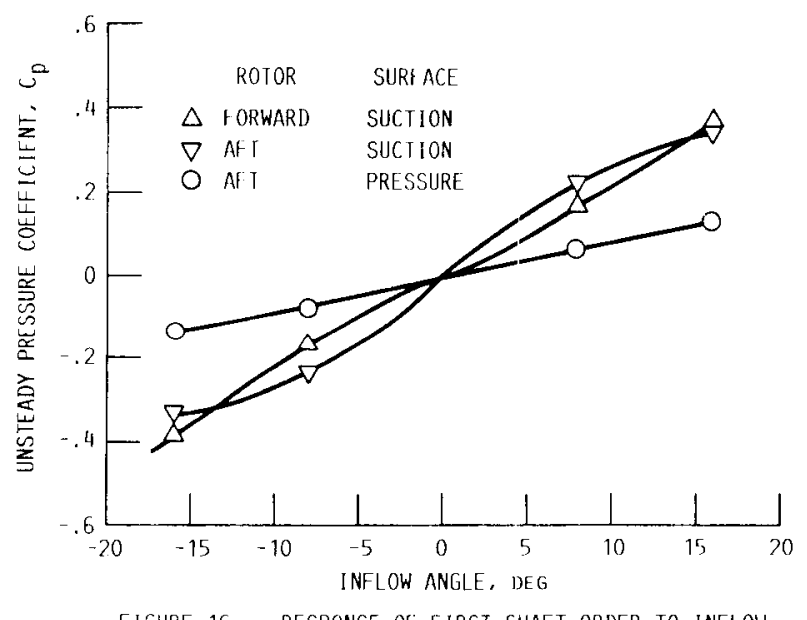

FIGURE 16 - RESPONSE OF FIRST CHAFT ORDIR TO INFLOW ANGLE, ROTAIIONAL SPEED, 90 I'ERCENT OF DESIGN. 


\begin{tabular}{|c|c|c|c|}
\hline \multicolumn{4}{|c|}{ Report Documentation Page } \\
\hline 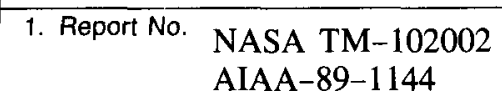 & 2. Government Accession No. & \multicolumn{2}{|c|}{ 3. Recipient's Catalog No. } \\
\hline \multicolumn{2}{|l|}{ 4. Title and Subtitle } & \multicolumn{2}{|l|}{ 5. Report Date } \\
\hline \multicolumn{2}{|c|}{$\begin{array}{l}\text { Unsteady Blade Pressure Measurements on a Model Counterrotation } \\
\text { Propeller }\end{array}$} & 6. Performing $\mathrm{C}$ & zation Code \\
\hline \multirow[t]{2}{*}{$\begin{array}{l}\text { 7. Author(s) } \\
\text { Laurence J. Heidelberg and Ri }\end{array}$} & Woodward & \multicolumn{2}{|c|}{$\begin{array}{l}\text { 8. Performing Organization Report No. } \\
\text { E-4684 }\end{array}$} \\
\hline & & \multicolumn{2}{|l|}{$\begin{array}{l}\text { 10. Work Unit No. } \\
535-03-01\end{array}$} \\
\hline \multirow{2}{*}{\multicolumn{2}{|c|}{$\begin{array}{l}\text { 9. Performing Organization Name and Address } \\
\text { National Aeronautics and Space Administration } \\
\text { Lewis Research Center } \\
\text { Cleveland, Ohio } 44135-3191\end{array}$}} & \multicolumn{2}{|c|}{ 11. Contract or Grant No. } \\
\hline & & \multirow{2}{*}{\multicolumn{2}{|c|}{$\begin{array}{l}\text { 13. Type of Report and Period Covered } \\
\text { Technical Memorandum }\end{array}$}} \\
\hline \multirow{2}{*}{\multicolumn{2}{|c|}{$\begin{array}{l}\text { 12. Sponsoring Agency Name and Address } \\
\text { National Aeronautics and Space Administration } \\
\text { Washington, D.C. 20546-0001 }\end{array}$}} & & \\
\hline & & \multicolumn{2}{|c|}{ 14. Sponsoring Agency Code } \\
\hline \multicolumn{4}{|c|}{$\begin{array}{l}\text { 15. Supplementary Notes } \\
\text { Prepared for the } 12 \text { th Aerocoustics Conference sponsored by the American Institute of Aeronautics and } \\
\text { Astronautics, San Antonio, Texas, April } 10-12,1989 \text {. }\end{array}$} \\
\hline \multicolumn{4}{|c|}{$\begin{array}{l}\text { 16. Abstract } \\
\text { In an exploratory effort an advanced counterrotation propeller instrumented with blade-mounted pressure } \\
\text { transducers was tested in the NASA Lewis } 9 \text { - by } 15 \text {-Foot Anechoic Wind Tunnel at a simulated takeoff and } \\
\text { landing speed of Mach } 0.20 \text {. The propeller's aft diameter was reduced to investigate possible noise reductions } \\
\text { resulting from reduced blade row interaction with the tip vortex. The propeller was tested at three blade row } \\
\text { spacings at fixed blade setting angles, at the maximum blade row spacing at higher blade setting angles and at } \\
\text { propeller axis angles attack to the flow up to } \pm 16^{\circ} \text {. A limited number of unsteady blade surface pressure } \\
\text { measurements were made on both rotors of the model counterrotation propeller. Emphasis was placed on } \\
\text { determining the effects of rotor-rotor interactions on the blade surface pressures. A unique method of processing } \\
\text { the pressure signals was developed that enables even weak interaction waveforms and spectra to be separated } \\
\text { from the total signal. The interaction on the aft rotor was many times stronger than that on the forward rotor. } \\
\text { The fundamental rotor interaction tone exhibited complicated behavior but generally increased with rotational } \\
\text { speed and blade setting angle and decreased with rotor spacing. With the propeller axis at an angle to the flow, } \\
\text { the phase response of the aft rotor appeared to be significantly affected by the presence of the forward rotor. }\end{array}$} \\
\hline $\begin{array}{l}\text { 17. Key Words (Suggested by Author(s)) } \\
\text { Counterrotation propeller } \\
\text { Rotor-rotor interaction } \\
\text { Unsteady blade pressure }\end{array}$ & $\begin{array}{r}\text { 18. Distribu } \\
\text { Unc } \\
\text { Subj }\end{array}$ & $\begin{array}{l}\text { Unlimited } \\
\text { ory } 71\end{array}$ & \\
\hline $\begin{array}{l}\text { 19. Security Classif. (of this report) } \\
\text { Unclassified }\end{array}$ & $\begin{array}{l}\text { 20. Security Classif. (of this page) } \\
\text { Unclassified }\end{array}$ & $\begin{array}{l}\text { 21. No of pages } \\
20\end{array}$ & $\begin{array}{l}\text { 22. Price } \\
\text { A03 }\end{array}$ \\
\hline
\end{tabular}

